\title{
Is There An Association Between Chronic Urticaria and Fibromyalgia Syndrome?
}

\author{
Pelin OKTAYOĞLU, ${ }^{1}$ Derya UÇMAK, ${ }^{2}$ Mehmet ÇAĞLAYAN, ${ }^{1}$ Demet UÇAR, ${ }^{1}$ Mehtap BOZKURT, \\ Serda EM, ${ }^{1}$ Levent YAZMALAR, ${ }^{1}$ Kemal NAS ${ }^{1}$ \\ ${ }^{1}$ Department of Physical Medicine and Rehabilitation, Medical Faculty of Dicle University, Diyarbakır, Turkey \\ ${ }^{2}$ Department of Dermatology, Medical Faculty of Dicle University, Diyarbakır, Turkey
}

\begin{abstract}
Objectives: Chronic urticaria (CU) and fibromyalgia (FM) are different types of diseases with unclear etiopathogeneses but share many clinical and histochemical features. This study aims to make a recognization on these features and examines whether patients with CU are also affected by FM.

Patients and methods: Forty patients with $\mathrm{CU}$ and 38 healthy controls were enrolled to this study. All of the participants were assessed according to the 1990 American College of Rheumatology (ACR) classification criteria for FM and asked questions regarding the clinical features of FM. The quality of life was assessed by the Nottingham Health Profile (NHP), while the psychological status was evaluated using the Hospital Anxiety and Depression Scale (HADS).

Results: The incidence of FM was higher among the patients with CU $(32.5 \%)$ than the controls $(10.5 \%)(p=0.019)$. We indicated that the patients with $\mathrm{CU}$ suffered restrictions regarding to quality of life as assessed by the NHP. NHP-sleep $(p=0.035)$, NHP-social isolation ( $p=0.032)$ and NHP-emotional reaction ( $p=0.027$ ) scores were significantly higher compared to HCs. The HADS-depression scores were also significantly higher in the patients with $\mathrm{CU}(\mathrm{p}=0.006)$. The patients with $\mathrm{CU}$ and concomitant FM had higher total NHP scores than those without FM ( $p<0.001)$.

Conclusion: Clinicians must be alerted to the possible coexistence of FM in CU patients. Patients with CU have higher rates of FM than the general population and this results in more restrictions in daily life in these patients than those with CU alone. Therefore, additional treatment protocols may be required to be implicated for the treatment of patients with both CU and FM.

Keywords: Chronic urticaria; fibromyalgia; psychological status; quality of life.
\end{abstract}

Urticaria is one of the most common skin diseases, and it is characterized by the rapid appearance of itchy wheals. In recent years, many subtypes of this disease have been identified. ${ }^{1}$ One example is chronic urticaria (CU), which is defined as the presence of urticarial symptoms beyond six weeks.

Autoimmunity is the source of $\mathrm{CU}$ in $45 \%$ of the patients ${ }^{2-6}$ but the etiology for the remaining $55 \%$ is still unknown. Thus, CU is considered to be "idiopathic" in these remaining patients. ${ }^{7}$ Thyroid antibodies may be associated with $\mathrm{CU}^{8}$ as well as hepatitis $\mathrm{A}$ and $\mathrm{B}$ and other viral and bacterial infections such as Helicobacter pylori, parasites, and neoplasia. ${ }^{9}$ Patients with $\mathrm{CU}$ are reported to suffer from a loss of energy, sleep disturbances, anxiety, and symptoms of depression along with reduced quality of life (QoL) with regard to mobility, home management, and work. ${ }^{10,11}$ Furthermore, CU shares many features with fibromyalgia (FM) regarding these and many other characteristics.

Fibromyalgia is a clinical condition with widespread pain lasting for at least three months and characteristic tender points on physical examination. It is usually accompanied by

Received: March 28, 2013 Accepted: July 02, 2013

Correspondence: Pelin Oktayoğlu, M.D. Dicle Üniversitesi Tıp Fakültesi Fizik Tedavi ve Rehabilitasyon Anabilim Dalı, 21280 Diyarbakır, Turkey.

Tel: +90 412 - 2488001 e-mail: plnftr@hotmail.com

Presented at the $10^{\text {th }}$ Turkish Rheumatology Symposium, April 11-14, 2013, Mugla, Turkey.

(O2014 Turkish League Against Rheumatism. All rights reserved. 
somatic, psychological, and emotional symptoms that include fatigue, sleep disturbances, cognitive difficulties, anxiety, and depressive disorders. ${ }^{12}$ Stress triggers the symptoms and affects the severity of symptoms in patients with both FM and CU..$^{13,14}$ Some pathological changes have been described in the skin biopsies of patients with FM as resembling the cellular and cytokine involvement in the biopsy specimens of patients with CU. ${ }^{15-19}$ In addition, it has been suggested that there is an autonomic dysfunction in patients with $\mathrm{FM}$ and $\mathrm{CU}$, and sympathomimetic amines may lead to improvement in the symptoms of the two diseases when there is a resistance to conventional therapies. ${ }^{20-23}$ Taking into account all of this information, we investigated whether patients with $\mathrm{CU}$ are also affected by FM.

\section{PATIENTS AND METHODS}

A total of 40 patients with CU (28 females, 12 males) and 38 healthy controls (HCs) (22 females, 16 males) were included in this study. Patients with a history of malignancy, diabetes mellitus (DM), congestive heart failure, acute or chronic infections, cerebrovascular diseases, alcohol abuse, major depression, rheumatological diseases, autoimmune thyroiditis, hypothyroidism, hyperthyroidism, or any other systemic disorders were excluded from the study. We obtained the informed consent of the patients prior to the beginning of this trial, and the study was carried out according to the Declaration of Helsinki and was approved by the Ethics Committee of our university.

\section{Assessment of the patients with $\mathrm{CU}$}

The patients' age, gender, use of medications, and duration of the disease were recorded, and a dermatologist also examined them to determine the possible causes of urticaria, such as drugs, food, insect bites, or other causative factors.

We also did a complete blood count $(\mathrm{CBC})$ and determined the erythrocyte sedimentation rate (ESR) along with the antistreptolysin-O (ASO), serum glucose, alanine aminotransferase, aspartate aminotransferase levels of the patients at the beginning of the study and took a stool sample to check for parasites. In addition, we also performed a urinalysis and hepatitis serology testing [anti- hepatitis C virus (anti-HCV), hepatitis B surface antigen (HbsAg)] while also determining rheumatoid factor (RF) and complement levels. We also evaluated the antinuclear and antithyroid microsomal antibodies. Additionally, each participant underwent a thyroid function test [thyroid-stimulating hormone (TSH) and free thyroxine], and physical urticaria and autologous serum tests were conducted on the patients with $\mathrm{CU}$. Furthermore, we obtained chest radiograms from all of the patients.

Three of the patients with $\mathrm{CU}$ had the histories of angioedema, two of the patients had the histories of Hashimoto thyroiditis. One of these patients also had positive autologous serum test. Five of the patients had high ASO antibody titres with negative culture of throat except for one patient with $\mathrm{CU}$. One of the patients had the history of chronic hepatitis $\mathrm{B}$ and one patient with $\mathrm{CU}$ had high serum levels of TSH. All of these patients were excluded at the beginning of the study.

\section{Assessment of the tender points}

The tender points were examined by palpation with the pulp of the thumb at a pressure of $4 \mathrm{~kg}$ according to the 1990 American College of Rheumatology (ACR) criteria for FM. ${ }^{12}$ A patient was considered to have a positive tender point when there was a feeling of mild or great pain. All of the patients were also asked questions about their complaints of chronic widespread pain, sleep disturbances, fatigue, morning stiffness, and swollen soft tissues, and they responded with a simple "yes" or "no".

\section{Assessment of functional status}

The Fibromyalgia Impact Questionnaire $(\mathrm{FIQ})^{24}$ was used to assess the severity of FM and functional status of the patients. The FIQ consists of 10 items, with the first item being related to the patient's ability to do daily work. The second and third items assess the patient's wellness over the last week and the number of days they were unable to work. The remaining seven items assess the patient's ability to work as well as pain, fatigue, tiredness, stiffness, anxiety, and depression. The Turkish version of the instrument has been shown to be valid and reliable. ${ }^{25}$

\section{Assessment of health-related QoL}

The QoL of all of the participants was assessed using the Nottingham Health Profile (NHP), ${ }^{26}$ and 
this contains the following six subgroups: energy, pain, physical mobility, sleep, emotional reactions, and social isolation. An adapted Turkish version of the NHP exists that has been deemed to be valid and reliable. ${ }^{27}$

\section{Assessment of the psychological status}

The symptoms of depression and anxiety were assessed by the Hospital Anxiety and Depression Scale (HADS), ${ }^{28}$ which consists of 14 items divided into two subscales of seven items each. Each subscale ranges in value from $0-21$ for either depression or anxiety. The validity and reliability of the Turkish version of the scale was proven by Aydemir et al. ${ }^{29}$

\section{Statistical analysis}

All analyses were performed using the Statistical Package for Social Sciences Software version 16.0 for Windows (SPSS Inc., Chicago, IL, USA). The data was expressed using mean \pm standard deviation (SD). Student's t-test was used to determine the differences in variables between the two groups, whereas a chi-square test was used to identify the differences in frequency between the categorical groups. Additionally, Fisher's exact test was used when the expected values were lower than five. A $p$ value of $<0.05$ was considered to be statistically significant.

\section{RESULTS}

There were no significant differences between the $\mathrm{CU}$ patients and the $\mathrm{HCs}$ with respect to age, gender, or body mass index (BMI). We also determined that the duration of urticarial symptoms ranged between 3 and 96 months in the patients with CU (Table 1).
Thirteen out of the 40 patients with CU (32.5\%) also had FM while four members of the HC group (10.5\%) were diagnosed with this syndrome. This difference was statistically significant $(p=0.019)$. Furthermore, $11(39.2 \%)$ out of the 28 female patients with $\mathrm{CU}$ were diagnosed with FM, whereas only three (13.6\%) of the female $\mathrm{HCs}$ received the same diagnosis. The ratio of FM was significantly higher in the female patients with $\mathrm{CU}$ compared with the females in the $\mathrm{HC}$ group ( $p=0.045)$. Moreover, thirteen patients (32.5\%) with CU had positive autologous serum test results, and seven of these (53.8\%) also had FM. Except for one female patient in the HC, all of the patients who were diagnosed with FM were previously aware of that fact.

The patients with $\mathrm{CU}$ had significantly more complaints involving morning stiffness $(p=0.016)$, chronic widespread pain $(p<0.001)$, sleep disturbances $(p=0.006)$, fatigue $(p<0.001)$, and swollen soft tissues $(p=0.009)$ than the HCs (Table 2). In addition, two male patients with $\mathrm{CU}$ complained of pain in 11 and 14 tender points, respectively while the total number of tender points in the female $\mathrm{CU}$ patients with concomitant FM ranged between 11 and 16 .

The participants also reported that $\mathrm{CU}$ affected their QoL by disturbing their sleep, restricting their social life, and altering their emotional reactions. The patients with $\mathrm{CU}$ also had significantly higher scores in the NHP-sleep $(p=0.035)$, NHP-social isolation $(p=0.032)$ and NHP-emotional reaction $(p=0.027)$ categories than the HCs (Table 3), and the total NHP scores were significantly higher in the patients with FM $(p<0.001)$ than those without this syndrome. However, no significant differences were found between the CU patients with and without FM with regard to the other subgroups of the NHP ( $>0.05)$.

\begin{tabular}{|c|c|c|c|c|c|}
\hline & \multicolumn{2}{|c|}{ Chronic urticaria $(n=40)$} & \multicolumn{2}{|c|}{ Healthy controls $(n=38)$} & \multirow[b]{2}{*}{$p$} \\
\hline & $\mathrm{n}$ & Mean \pm SD & $\mathrm{n}$ & Mean \pm SD & \\
\hline Age (years) & & $32.5 \pm 11.4$ & & $31.6 \pm 10.2$ & NS \\
\hline \multicolumn{6}{|l|}{ Gender } \\
\hline Female & 28 & & 22 & & \\
\hline Male & 12 & & 16 & & NS \\
\hline Body mass index $\left(\mathrm{kg} / \mathrm{m}^{2}\right)$ & & $25.1 \pm 4.7$ & & $24.1 \pm 4.5$ & NS \\
\hline Duration of $\mathrm{CU}$ in month & & $21.7 \pm 23.0$ & & - & - \\
\hline
\end{tabular}




\begin{tabular}{|c|c|c|c|c|c|}
\hline & \multicolumn{2}{|c|}{ Chronic urticaria $(n=40)$} & \multicolumn{2}{|c|}{ Healthy controls ( $\mathrm{n}=38$ ) } & \multirow[b]{2}{*}{$p$} \\
\hline & $\mathrm{n}$ & $\%$ & $\mathrm{n}$ & $\%$ & \\
\hline Fibromyalgia & 13 & 32.5 & 4 & 10.5 & $0.019 *$ \\
\hline Morning stiffness & 10 & 25 & 2 & 5.2 & $0.016^{*}$ \\
\hline Chronic widespread pain & 21 & 52.5 & 5 & 13.1 & $<0.001$ \\
\hline Sleep disturbance & 25 & 62.5 & 12 & 31.5 & $0.006^{*}$ \\
\hline Fatigue & 29 & 72.5 & 8 & 21 & $<0.001$ \\
\hline Swollen soft tissue & 21 & 52.5 & 1 & 2.6 & $0.009^{*}$ \\
\hline
\end{tabular}

Table 3. Assessment of disease-related quality of life and the psychological status of patients with chronic urticaria and the healthy controls

\begin{tabular}{|c|c|c|c|}
\hline & Chronic urticaria $(\mathrm{n}=40)$ & Healthy controls $(n=38)$ & \\
\hline & Mean \pm SD & Mean \pm SD & $p$ \\
\hline HADS-anxiety score & $5.9 \pm 7.05$ & $5.2 \pm 3.9$ & 0.562 \\
\hline HADS-depression score & $5.1 \pm 2.8$ & $3.1 \pm 3.2$ & $0.006^{*}$ \\
\hline NHP-sleep score & $33.0 \pm 31.5$ & $19.1 \pm 24.9$ & $0.035^{*}$ \\
\hline NHP-social isolation score & $26.0 \pm 36$ & $11.0 \pm 22.6$ & $0.032^{*}$ \\
\hline NHP-emotional reaction score & $34.1 \pm 38.7$ & $17.5 \pm 24.4$ & $0.027^{*}$ \\
\hline Fibromyalgia impact questionnaire & $30.4 \pm 22.2$ & $17.0 \pm 19.2$ & $0.006^{*}$ \\
\hline
\end{tabular}

The psychological status of the patients with $\mathrm{CU}$ was significantly different with respect to depression compared with the HCs, and the HADS-depression scores were significantly higher $(p=0.006)$ for the $\mathrm{CU}$ patients. On the other hand, there was significant difference regarding the HADS-anxiety scores between the two groups $(\mathrm{p}=0.562)$ (Table 3$)$. Moreover, the depression and anxiety scores were not significantly different between the $\mathrm{CU}$ patients with FM and those without $(p=0.070, p=0.069$ respectively).

\section{DISCUSSION}

In the present study, we indicated that the patients with $\mathrm{CU}$ had FM at higher rates than the $\mathrm{HC}$ group. This proportion was particularly higher when male patients were excluded from the two study groups. To our knowledge, there has been no previous trial related to the prevalence of FM among the general Turkish population, but the prevalence of FM that we found among our patients with $\mathrm{CU}$ was higher than the general prevalence of FM that has been reported in the literature. ${ }^{30}$ In a study among Turkish women between the ages of 20-64, the prevalence of FM was reported to be $3.6 \% .{ }^{31}$ Our results indicated a higher prevalence rate of FM among the female patients in the CU group than among the Turkish female population as a whole.

Torresani et al. ${ }^{32}$ included 126 patients with $\mathrm{CU}$ in their study and showed that $70 \%$ of those with $\mathrm{CU}$ also had FM, This proportion is almost two times higher than our results, but this difference may be explained by the different study designs that were used. Patients with DM, thyroid dysfunctions, hematological abnormalities, autoimmune disorders, and other systemic diseases were all included in their study, but we excluded those with a history of any systemic, inflammatory, or autoimmune disorders. Unlike Torresani et al. study, ${ }^{32}$ we also assessed symptoms such as sleep disturbances, fatigue, morning stiffness, and swollen soft tissues in the patients with $\mathrm{CU}$, since they usually accompany $\mathrm{FM},{ }^{12,33}$ and found that the frequency of those symptoms was higher in the patients with $\mathrm{CU}$ than for the HCs. Furthermore, we demonstrated restrictions in the QoL in patients with $\mathrm{CU}$. In addition, the patients who had both $\mathrm{CU}$ and FM had higher total NHP scores than those who only had CU. In a study investigating the QoL 
in patients with $\mathrm{CU}$, O'Donell et al. ${ }^{11}$ also used the NHP questionnaire and identified restrictions in the areas of mobility, sleep, energy, social isolation, and emotional reactions in CU patients. Some authors have suggested that patients with this skin condition suffer from both depression and anxiety, ${ }^{34,35}$ but only the depression scores were higher among our patients with $\mathrm{CU}$.

We searched the literature using the keywords "chronic widespread pain" and "chronic urticaria" and found only one article, and this was related to adult-onset Still's disease and urticaria. In our study, we demonstrated that there were high rates of chronic widespread pain (52.5\%) in the CU patients compared with the HCs. Some of these patients with chronic widespread pain were not diagnosed with FM probably because the 1990 ACR criteria for the classification of FM was used. ${ }^{12}$ Therefore, using the 2010 ACR preliminary diagnostic criteria ${ }^{36}$ for FM may help include patients with chronic widespread pain in the assessment, which may eventually increase the rate of patients who have both $\mathrm{CU}$ and FM.

Chronic urticaria and FM share many histopathological and clinical signs and symptoms. Blanco et al. ${ }^{15}$ investigated the skin biopsies of patients with FM and found increased numbers of mast cells in the papillary dermis of all the patients with FM, whereas the control group had normal results. Similar studies were also carried out on patients with $\mathrm{CU}$, and these revealed the same evidence of increased numbers of mast cells versus the normal skin biopsy findings in the control group. ${ }^{16,17}$ In another trial related to the skin biopsies of patients with FM, Salemi et al. ${ }^{18}$ showed that a high proportion of the patients had increased immunoreactivity for tumor necrosis factor alpha (TNF- $\alpha$ ) in the biopsy specimens. Similarly, Hermes et al. ${ }^{19}$ demonstrated that there was a high immunoreactivity for TNF- $\alpha$ in all types of urticaria, whereas none of the control patients had an immunohistochemical expression of TNF- $\alpha$ in the biopsy specimens.

Another common feature of $\mathrm{CU}$ and FM was demonstrated by the successful results achieved when administering sympathomimetic amines when there was resistance to conventional therapies. ${ }^{22,23}$ In addition, it is hypothesized that patients with $\mathrm{CU}$ have an inappropriate sympathetic nervous system response to the increase in hydrostatic pressure while standing. ${ }^{23}$ Furthermore, some authors have suggested that there is a reduced capability to enhance the sympathetic activity in vessels due to the autonomic dysfunction in patients with FM. ${ }^{20,21}$

The pathogenesis of $\mathrm{CU}$ and FM is still unknown, ${ }^{17,37}$ but it is difficult to claim that $\mathrm{CU}$ and FM originate from the same etiopathogenesis. Furthermore, this study did not aim to prove such a claim; however, we still noticed remarkable similarities between the two diseases. Hence, future trials based on clinical and laboratory evidence should be conducted to help explain the relationship between $\mathrm{CU}$ and FM.

\section{Conclusion}

Clinicians must be alerted to the possible coexistence of FM in patients with $\mathrm{CU}$ and consult a rheumatologist accordingly because these patients may need additional treatment. Therefore, they must be assessed to make a certain diagnosis of FM, especially since patients with both FM and $\mathrm{CU}$ have a more restricted QoL than those with only $\mathrm{CU}$.

\section{Declaration of conflicting interests}

The authors declared no conflicts of interest with respect to the authorship and/or publication of this article.

\section{Funding}

The authors received no financial support for the research and/or authorship of this article.

\section{REFERENCES}

1. Zuberbier T, Maurer M. Urticaria: current opinions about etiology, diagnosis and therapy. Acta Derm Venereol 2007;87:196-205.

2. Hide M, Francis DM, Grattan CE, Hakimi J, Kochan JP, Greaves MW. Autoantibodies against the highaffinity IgE receptor as a cause of histamine release in chronic urticaria. N Engl J Med 1993;328:1599604.

3. Niimi N, Francis DM, Kermani F, O'Donnell BF, Hide M, Kobza-Black A, et al. Dermal mast cell activation by autoantibodies against the high affinity $\mathrm{IgE}$ receptor in chronic urticaria. $J$ Invest Dermatol 1996;106:1001-6. 
4. Fiebiger E, Maurer D, Holub H, Reininger B, Hartmann G, Woisetschläger $M$, et al. Serum IgG autoantibodies directed against the alpha chain of Fc epsilon RI: a selective marker and pathogenetic factor for a distinct subset of chronic urticaria patients? J Clin Invest 1995;96:2606-12.

5. Tong LJ, Balakrishnan G, Kochan JP, Kinét JP, Kaplan AP. Assessment of autoimmunity in patients with chronic urticaria. J Allergy Clin Immunol 1997;99:461-5.

6. Kikuchi Y, Kaplan AP. Mechanisms of autoimmune activation of basophils in chronic urticaria. J Allergy Clin Immunol 2001;107:1056-62.

7. Kaplan AP, Greaves M. Pathogenesis of chronic urticaria. Clin Exp Allergy 2009;39:777-87.

8. Leznoff A, Sussman GL. Syndrome of idiopathic chronic urticaria and angioedema with thyroid autoimmunity: a study of 90 patients. J Allergy Clin Immunol 1989;84:66-71.

9. Najib U, Sheikh J. The spectrum of chronic urticaria. Allergy Asthma Proc 2009;30:1-10.

10. Staubach P, Eckhardt-Henn A, Dechene M, Vonend A, Metz M, Magerl M, et al. Quality of life in patients with chronic urticaria is differentially impaired and determined by psychiatric comorbidity. Br J Dermatol 2006;154:294-8.

11. O'Donnell BF, Lawlor F, Simpson J, Morgan M, Greaves MW. The impact of chronic urticaria on the quality of life. Br J Dermatol 1997;136:197-201.

12. Wolfe F, Smythe HA, Yunus MB, Bennett RM, Bombardier C, Goldenberg DL, et al. The American College of Rheumatology 1990 Criteria for the Classification of Fibromyalgia. Report of the Multicenter Criteria Committee. Arthritis Rheum 1990;33:160-72.

13. Van Houdenhove $\mathrm{B}$, Egle $\mathrm{U}$, Luyten $\mathrm{P}$. The role of life stress in fibromyalgia. Curr Rheumatol Rep 2005;7:365-70.

14. Malhotra SK, Mehta V. Role of stressful life events in induction or exacerbation of psoriasis and chronic urticaria. Indian J Dermatol Venereol Leprol 2008;74:594-9.

15. Blanco I, Béritze N, Argüelles M, Cárcaba V, Fernández $\mathrm{F}$, Janciauskiene $\mathrm{S}$, et al. Abnormal overexpression of mastocytes in skin biopsies of fibromyalgia patients. Clin Rheumatol 2010;29:1403-12.

16. Elias J, Boss E, Kaplan AP. Studies of the cellular infiltrate of chronic idiopathic urticaria: prominence of T-lymphocytes, monocytes, and mast cells. J Allergy Clin Immunol 1986;78:914-8.

17. Nettis E, Dambra P, Loria MP, Cenci L, Vena GA, Ferrannini A, et al. Mast-cell phenotype in urticaria. Allergy 2001;56:915.

18. Salemi S, Rethage J, Wollina U, Michel BA, Gay RE, Gay $\mathrm{S}$, et al. Detection of interleukin 1beta (IL-1beta), IL-6, and tumor necrosis factor-alpha in skin of patients with fibromyalgia. J Rheumatol 2003;30:146-50.
19. Hermes B, Prochazka AK, Haas N, Jurgovsky K, Sticherling M, Henz BM. Upregulation of TNF-alpha and IL-3 expression in lesional and uninvolved skin in different types of urticaria. J Allergy Clin Immunol 1999;103:307-14.

20. Staud R. Autonomic dysfunction in fibromyalgia syndrome: postural orthostatic tachycardia. Curr Rheumatol Rep 2008;10:463-6.

21. Furlan R, Colombo S, Perego F, Atzeni F, Diana A, Barbic $F$, et al. Abnormalities of cardiovascular neural control and reduced orthostatic tolerance in patients with primary fibromyalgia. J Rheumatol 2005;32:1787-93.

22. Check JH, Gentlesk MJ, Falanga V. Sympathomimetic amines in the treatment of chronic urticaria: two case reports. Cutis 1984;34:388-90.

23. Check JH, Katsoff D, Kaplan H, Liss J, Boimel P. A disorder of sympathomimetic amines leading to increased vascular permeability may be the etiologic factor in various treatment refractory health problems in women. Med Hypotheses 2008;70:671-7.

24. Burckhardt CS, Clark SR, Bennett RM. The fibromyalgia impact questionnaire: development and validation. $\mathrm{J}$ Rheumatol 1991;18:728-33.

25. Sarmer S, Ergin S, Yavuzer G. The validity and reliability of the Turkish version of the Fibromyalgia Impact Questionnaire. Rheumatol Int 2000;20:9-12.

26. Hunt SM, McKenna SP, McEwen J, Williams J, Papp E. The Nottingham Health Profile: subjective health status and medical consultations. Soc Sci Med A 1981;15:221-9.

27. Kücükdeveci AA, McKenna SP, Kutlay S, Gürsel Y, Whalley D, Arasil T. The development and psychometric assessment of the Turkish version of the Nottingham Health Profile. Int J Rehabil Res 2000;23:31-8.

28. Zigmond AS, Snaith RP. The hospital anxiety and depression scale. Acta Psychiatr Scand 1983;67:361-70.

29. Aydemir O, Guvenir T, Kuey L, Kultur S. Validity and reliability of Turkish version of hospital anxiety and depression scale. Turk Psikiyatri Derg 1997;8:280-7.

30. Wolfe F, Ross K, Anderson J, Russell IJ, Hebert L. The prevalence and characteristics of fibromyalgia in the general population. Arthritis Rheum 1995;38:19-28.

31. Topbas M, Cakirbay H, Gulec H, Akgol E, Ak I, Can G. The prevalence of fibromyalgia in women aged 20-64 in Turkey. Scand J Rheumatol 2005;34:140-4.

32. Torresani C, Bellafiore S, De Panfilis G. Chronic urticaria is usually associated with fibromyalgia syndrome. Acta Derm Venereol 2009;89:389-92.

33. Clauw DJ. The pathogenesis of chronic pain and fatigue syndromes, with special reference to fibromyalgia. Med Hypotheses 1995;44:369-78.

34. Hashiro M, Okumura M. Anxiety, depression, psychosomatic symptoms and autonomic nervous function in patients with chronic urticaria. J Dermatol Sci 1994;8:129-35. 
35. Engin B, Uguz F, Yilmaz E, Ozdemir M, Mevlitoglu I. The levels of depression, anxiety and quality of life in patients with chronic idiopathic urticaria. J Eur Acad Dermatol Venereol 2008;22:36-40.

36. Wolfe F, Clauw DJ, Fitzcharles MA, Goldenberg DL, Katz RS, Mease $\mathrm{P}$, et al. The American
College of Rheumatology preliminary diagnostic criteria for fibromyalgia and measurement of symptom severity. Arthritis Care Res (Hoboken) 2010;62:600-10.

37. Staud R. Fibromyalgia pain: do we know the source? Curr Opin Rheumatol 2004;16:157-63. 